\title{
JUAN ESLAVA GALÁN
}

\author{
Fl Yermo \\ (Traducción de la obra de T. S. Eliot, 1974) \\ With an Introduction by Nadia López-Peláez Akalay \\ The Grove 25 (2018-2020)
}

\section{El Yermo: The Writer at Another Writer's Poem. An Introduction to Juan Eslava's Translation of The Waste Land by T. S. Eliot}

“¿Qué raíces se aferran, qué tallos brotan/ de este escombro?” This question might probably represent one of the highest peaks in the renowned writer Prof. Juan Eslava's translation of Eliot's masterpiece. Here, I believe Juan Eslava shows his deep commitment to the poem through his full understanding of Eliot's text, whilst preserving the originality, creativity and intellect that fits a writer like himself. Concerning the main question, it is too true that no life can grow from a barren soil - from a broken culture - and Juan Eslava grasps this notion all throughout his outstanding translation. The entrapment of society within unworthy living conditions, the suffocating waves where the people's hopes and expectations drown are all brilliantly depicted in the literary translation by Eslava: "No encuentro al Ahorcado. Guárdese de la muerte por agua. Veo multitudes de gente caminando en círculo", where Madame Sosostris sees nothing but disaster and despair.

Baudelaire's Paris as "Ciudad de ensueño" is an interesting approach to Eliot's "unreal city", where what is depicted next are in fact nightmarish visions of crippled crowds, fallen aspirations, and death. This choice of words goes beyond the first perception readers might get from the excerpt, further emphasising the striking contrast of what is, what ought to be, and what will never be: the magnificence of Paris. Opposing a word that includes the meaning of "dream" to a nightmare is part of the essence of the poem, and it goes beyond that: these are the roots of Eliot's poetic persona, and what drives them to find a way out, to blend with nature and to comprehend their atrocious existence - for there is, buried deeply in the genius of the speaker in the poem, an almost imperceptible 
yearning and hoping - something which Juan Eslava seems to grasp magnificently.

This extract gives evidence of the capability of the writer when it comes to his talent and proficiency concerning translation:

Cual trono bruñido, la Sede que ocupaba

resplandecía sobre el mármol. Sobre forjados estandartes

gravitaban los sazonados pámpanos del espejo

Here, Juan Eslava displays a mastery over the internal rhyme and rhythm of the original poem, mainly through alliteration and a precise use of the stress in words, which endows the translated poem with a flow that makes it easier to read and to listen to. The alliterated /s/ in these lines is utilised in the poem to emphasise the nobleness in the description of Eliot's Queen as a Shakespearean Cleopatra. It is in this instance, and many others, that the reader becomes aware of the authorial hand of the writer as a translator, who demonstrates sensitivity not only towards a generalised meaning, but towards the artistic form, too. Both authors manage to reveal, through the musicality in their lines and the, paradoxically, freely drifting streams of verse, the poetic persona's depiction of a desolate land and intense yearnings for the wheel to turn.

In the following "A mi espalda, con una fría ráfaga, percibo/ el chasqueo de los huesos y la carcajada estentórea", it is "chasqueo" that stands out the most, as within Eliot's lines the reader is able to perceive the poetic persona's echo of Andrew Marvell's “But at my back I always hear/ Time's wingèd chariot hurrying near", from To His Coy Mistress. Juan Eslava, in his translation, seems determined to keep the reverberating notion of the clatter of the horse-drawn carriage, that demonstrates his willingness to help the aware reader seize the allusion made in the original poem. Another manifestation of Juan Eslava's high regard for the text as a work of literature, and not as merely a text to translate, is shown in his lines "él lloró. Me prometió recomenzar. / Yo ni despegué los labios. ¿De qué me iba a quejar?", where he identifies Eliot's canonical rhyme in "after the event [...] what should I resent?", and internal rhyme, in "comment", "event", "resent", and endeavours to maintain it. In addition, Eslava's lines "Tú que giras el timón oteando a barlovento", illustrate how the Spanish writer preserves the double connotation in Eliot's line of the symbolic Wheel, in "giras" and "oteando" — and certainly in "timón", which is the "wheel". These words harmonise with the many references to the swirling "whirlpool" where humanity has fallen in the poem or rather, the whirlpool that $i$ s the poem. This extract depicts, in a similar manner to the original work, the enticing, and yet pernicious descent into hell: 
Una mujer tensó su endrina cabellera y pulsó suave música en tan sutiles cuerdas y murciélagos con rostros infantiles en el fulgor violeta chillaban y aleteaban y se colgaban cabeza abajo por los oscuros antros

The Spanish author embraces the perception of Eliot's poetic persona as the effortless, and almost soothing, downward spiral into self-ruination that had been constantly foregrounded and forewarned along the poem.

The translation concludes with "Me senté en la orilla/ a pescar, con la árida llanura a mi espalda/ ¿Pondré en orden mis tierras finalmente?” which prevails as the culminating gist that had been traced in the translation by Juan Eslava. These lines reverberate with the fundamental concepts of the poem as it deals with the remnants of a disintegrated society, and with what endures of its own self. A figurative writer (referred to as the quester, or the Fisher King in the poem) sits cultivating his mind, with fragmented pieces of scribbles piled heedlessly behind them, as they venture to infer the truth that lies at the root of it all. Juan Eslava in his translation entitled El Yermo - an unsurprisingly original title which again shows the inventive mind of the writer at work - is able to fathom and convey a deep meaning within the seemingly shattered fragments of the literary work in Eliot's The Waste Land. All of this reveals his skill, not only in his attempt to provide the accuracy in meaning of a literary work, but in his determination to convey the magnitude of the art of writing, too.

Nadia López-Peláez Akalay 


\title{
I. EL SEPELIO DE LOS MUERTOS
}

\author{
Abril, el mes más cruel, engendra \\ lilas en el erial, confunde \\ memoria y deseo, revive \\ las torpes raíces con lluvias de primavera. \\ El invierno nos mantuvo abrigados, olvidó \\ a la tierra en la nieve, alentó \\ un hálito de vida en los secos tubérculos. \\ Cayó el verano por sorpresa sobre el Starnbergsee \\ con un chaparrón. Nos demoramos bajo los pórticos \\ y cuando escampó, proseguimos al sol hacia el Hofgarten, y tomamos café y \\ estuvimos una hora charlando. \\ Bin gar keine Russin, stamm' aus Litauen, echt deutsch. \\ $Y$, de niños, estando en casa de mi primo el archiduque, \\ él me sacó en trineo \\ y me asusté. ¡Marie, \\ Marie, agárrate fuerte! Y allá que íbamos cuesta abajo. En las montañas una se \\ siente libre. \\ Me tiro casi toda la noche leyendo y en invierno voy al sur
}

¿Qué raíces se aferran, qué tallos brotan

de este escombro? Hijo del hombre,

no lo puedes decir, ni adivinar, porque sólo conoces

un montón de rotas imágenes en las que el sol se estrella, y el árbol muerto no da

cobijo, ni el grillo alivio

ni se percibe el agua rumorosa en la piedra seca. Sólo

hay sombra bajo esta roca roja,

(cobíjate en la sombra de esta roca roja),

y te mostraré algo diferente

de tu sombra matinal persiguiéndote

o de tu sombra que sale a tu encuentro al atardecer;

te mostraré el miedo en un puñado de polvo.

Frisch weht der Wind

Der Heimat zu.

Mein Irisch Kind,

Wo weilest du?

"Me ofreciste jacintos por primera vez hace un año;

me llamaban la chica de los jacintos".

Sin embargo, cuando regresamos, ya tarde, del jardín de los jacintos,

florecidos tus brazos y húmedo tu cabello, no podía 
articular palabra y me fallaban los ojos, no estaba ni vivo ni muerto, ni sabía nada, mirando en el luminoso corazón, el silencio. Oed'und leer das Meer.

Madame Sosostris, la famosa adivina, pilló un catarro tremendo, sin embargo pasa por ser la mujer más sapiente de Europa, con una sobada baraja de cartas. Aquí, dijo, está su carta, el Marinero Fenicio ahogado, (¡Contemplad las perlas que sus ojos fueron!) Aquí está Belladona, la Dama de las Rocas, la señora de las situaciones.

Aquí el Hombre de los Tres Bastos y aquí la Rueda, y aquí el mercader tuerto, y esta carta, que está en blanco, es algo que lleva a la espalda, y que me está vedado contemplar. No encuentro al Ahorcado. Guárdese de la muerte por agua. Veo multitudes de gente caminando en círculo. Gracias. Si ve a mi querida señora Equitone dígale que le llevaré el horóscopo personalmente: ¡Hay que precaverse en los tiempos que corren!

Ciudad de ensueño.

Bajo la niebla turbia de un amanecer invernal, una multitud fluía por el puente de Londres, tantos que nunca hubiera imaginado que la muerte hubiese deshecho a tantos.

Exhalaban suspiros breves y espaciados, y cada cual iba con la mirada fija en los pies.

Ascendían cuesta arriba y bajaban por la calle King William,

hacia donde Santa Mary Woolnoth daba las horas con un sonido lóbrego en la última campanada de las nueve.

Allí vi a uno que conocía y lo paré, gritándole: "!Stetson!

Tú, que estabas conmigo en las naves de Milas!

Oye: aquel cadáver que plantaste en tu jardín el año pasado, ¿Ha empezado ya a retoñar? ¿Florecerá este año?

¿O lo habrá malogrado una helada imprevista? ¡Ah, llévate de aquí al Perro, ese amigo del hombre, volverá a desenterrarlo con las uñas!

!Tú! Hypocrite lecteur! -mon semblable,- mon frère!" 


\section{UNA PARTIDA DE AJEDREZ}

Cual trono bruñido, la Sede que ocupaba

resplandecía sobre el mármol. Sobre forjados estandartes

gravitaban los sazonados pámpanos del espejo,

(Desde los que oteaba un dorado Cupido

y otro recataba los ojos bajo el ala)

que geminaba las siete llamas de la ménora

reflejando sus resplandores sobre el mármol como si

el destello de las joyas fuera a su encuentro

desde los guarnecidos cofres fastuosamente revestidos.

En no cerrados pomos de marfil y veteados cristales

se remansaban los extractos de exóticos perfumes,

bálsamos, polvos y esencias embriagaban, confundían

y condensaban un ámbito de olores mecidos por la brisa refrescante de la galería y ascendían

inflamando los agudos pábilos de las velas.

El humo que esparcían hacia el artesonado

inspiraba las tallas del repujado techo.

Enormes sándalos marinos de cobre incrustados

destellaban verdes y naranjas, enmarcados por veteados

mármoles

y en esta ambigua luz ondulaba un modelado delfín.

Sobre la antigua ménsula del hogar se abría, como ventana asomada a una escena silvestre,

la metamorfosis de Filomela, tan brutalmente forzada

por el bárbaro rey; el ámbito todo del desierto

latía con los inviolables trinos del ruiseñor

y ella seguía gritando -y aun gira el mundo-

"Tchiu, Tchiu" a los salaces oídos.

Y otros marchitos muñones del tiempo

se relataban en los lienzos, formas atónitas

se inclinaban asomándose, silenciando el ámbito

encerrado.

Pasos se deslizaban por la escalera.

A la luz de la lumbre, bajo el cepillo, su cabello

era una cegadora cascada

hervía de palabras y luego cruelmente enmudecía.

"Esta noche estoy fatal de los nervios. Fatal, sí. Quédate conmigo Háblame. ¿Por qué no hablas nunca? Habla.

¿En qué estás pensando? ¿Qué piensas? ¿Eh?

Nunca sé lo que estás pensando. Piensa" 
Pienso que estamos en el callejón de las ratas donde los muertos perdieron sus huesos.

"¿Qué es ese ruido?"

El viento bajo la puerta.

"¿Y ese ruido de ahora? ¿Qué hace el viento?"

Nada. Sigue sin hacer nada

\section{¿No}

sabes nada? ¿No ves nada? ¿No recuerdas

nada?"

Recuerdo

las perlas que sus ojos fueron.

¿¿Estás vivo o muerto? ¿Es que no tienes nada en la cabeza?"

\section{Pero}

Oh, Oh, Oh, Oh esa musiquilla shakesperiana

Es tan elegante,

Tan inteligente.

"¿Qué hago ahora? ¿Qué haré?"

Me echaré a la calle tal como estoy,

con estos pelos, así y daré una vuelta. ¿Qué vamos a hacer mañana?

¿Qué vamos a hacer nunca?"

$\mathrm{y}$, caso de que llueva, un coche cerrado a las cuatro.

El agua caliente a las diez

Y nos echaremos una partida de ajedrez.

Apretando los ojos sin párpados en espera de que alguien

llame a la puerta.

Cuando licenciaron al marido de Lil, le dije,

no me anduve con rodeos, me fui a ella y le dije,

POR FAVOR, DENSE PRISA QUE ES HORA

ahora que Albert está de vuelta arréglate un poco.

Querrá saber qué has hecho de aquel dinero que te dio

para que te arreglaras la dentadura. Te lo dio, estaba yo delante

Sácatelos todos, Lil, y ponte una dentadura flamante, puedo jurar que te lo dijo, que no aguantaba verte así.

Ni yo tampoco lo aguanto, añadí. Y piensa en el pobre Albert,

se ha tirado cuatro años en el ejército, querrá pasárselo bien,

y si no se lo das tú ya habrá otras dispuestas, le dije.

¡Ah!, Así que hay otras, dijo ella. Algo de eso hay, respondí.

Entonces ya sé a quién agradecérselo, dijo echándome una mirada furiosa. POR FAVOR, DENSE PRISA QUE ES HORA.

Si no te gusta lo que te digo, sigue así, le dije. 
Otras pueden escoger si tú no puedes.

Pero si Albert te deja plantada no será porque no te avisé.

Debería darte vergüenza, le dije, parecer tan rancia.

(Sólo cumplía treinta y uno).

No lo puedo remediar, me dijo compungida,

la culpa la tienen aquellas píldoras para abortar, dijo.

(Ya ha tenido cinco hijos y por poco no lo cuenta cuando tuvo a George).

El boticario dijo que todo iría bien pero la verdad es que nunca he vuelto a ser la misma.

Qué tonta eres, dije.

Bueno, si Albert no se contiene aguántate, le dije,

¿Para qué vas a casarte si no quieres hijos?

POR FAVOR, DENSE PRISA QUE ES HORA.

Bueno pues aquel domingo Albert estaba en casa por fin $\mathrm{y}$ comieron jamón hervido,

y me invitaron a cenar para que lo saborease calentito.

POR FAVOR, DENSE PRISA QUE ES HORA

POR FAVOR, DENSE PRISA QUE ES HORA

Buenas noches, Bill. Buenas noches, Lou. Buenas noches, May. Buenas noches.

$\mathrm{Ea}$, Buenas noches. Buenas noches.

Buenas noches, señoras, buenas noches, dulces señoras, buenas noches, buenas noches.

minervilla

\section{EL SERMÓN DEL FUEGO}

La pérgola del río está deshecha: mil dedos vegetales se aferran a la blanda ribera y la penetran. El viento atraviesa la parda tierra, ignorado. Las ninfas se han marchado.

¡Oh, dulce Támesis, atempera tu marcha hasta que acabe mi canto!

El río ya no lleva cascos de botellas ni papeles de liar bocadillos,

ni pañuelos de seda, ni cajas de cartón, ni colillas

ni algún otro testigo de noches veraniegas. Las ninfas se han marchado.

Y sus amigos, los alegres vástagos de papás preeminentes,

se fueron sin dejar señas. 
A orillas del Lemon me senté a llorar ...

Dulce Támesis, atempera tu marcha hasta que acabe mi canto.

Dulce Támesis, atempera tu marcha, no hablaré alto ni mucho.

A mi espalda, con una fría ráfaga, percibo

el chasqueo de los huesos y la carcajada estentórea.

Una rata se deslizó suavemente entre los matorrales arrastrando su viscosa tripa hasta la orilla mientras yo pescaba en el canal mortecino en un atardecer invernal, por detrás de los depósitos del gas

meditando sobre lo del naufragio de mi hermano, el rey y sobre la muerte de mi padre, rey antes que él.

Blancos cuerpos desnudos sobre el barro de la orilla y huesos apilados en el polvo de un angosto sótano perturbados tan sólo por el trasiego de las ratas, año tras año.

Pero a mi espalda alcanzo a percibir de vez en cuando un clamor de bocinas y motores que llevarán

a Sweeney hasta la señora Porter en primavera.

Ah, la brillante luna resplandecía por encima de la señora Porter

y por encima de su hija

estaban lavándose los pies con sifón

Et $O$ ces voix d'enfants, chantant dans la coupole!

Chiu chiu chiu

tchiu tchiu tchiu tchiu tchiu tchiu

tan brutalmente forzada.

Tereo

Ciudad de ensueño

bajo la niebla turbia de un mediodía invernal el señor Eugénides, mercader en Esmirna, sin afeitar, con un bolsillo lleno de pasas fletadas para Londres: albaranes en regla, me propuso en detestable francés que almorzáramos en el hotel de la calle Cannon y pasáramos un fin de semana en el Metropole. 
A la hora violeta cuando los ojos y la espalda se alzan del escritorio, cuando el motor humano aguarda ronroneando como el de un taxi, Yo, Tiresias, aunque ciego, latiendo entre dos vidas, viejo con ajados pechos de hembra, veo

a la hora violeta, la hora de la tarde que empuja hacia el hogar y atrae al marinero a tierra desde la mar. La mecanógrafa está de vuelta a la hora del té, recoge lo del desayuno, enciende

la estufa y abre unas latas.

Tras los cristales, comprometedoramente desplegadas, sus combinaciones tendidas perciben los rayos de un último sol.

Sobre el diván se confunden (que será cama nocturna), medias, pantuflas, blusas y sostenes.

Yo, Tiresias, un viejo de exhaustas ubres me percaté de la escena y adiviné el desenlace; también yo esperé al invitado.

Él, el joven furunculoso, llega

un chupatintas de oficina de poca monta, con expresión insolente

un don nadie que luce su descaro

como un millonario de Bradford su chistera.

Ahora es el momento propicio, y él lo advierte, han rematado la cena, ella está cansada y aburrida, procura calentarla con caricias si no deseadas, consentidas.

Encendido y resuelto se va al grano sin defensa que estorbe sus manos impacientes; su vanidad no exige que la otra participe se conforma de sobre con que se deje hacer. ( $Y$ yo, Tiresias, he padecido antes todo lo acaecido en este mismo diván o lecho; yo que me he sentado a la sombra de las murallas tebanas, yo que he caminado entre los más humildes muertos). Concede un último beso condescendiente, sale a tientas y encuentra la escalera a oscuras ...

Ella se vuelve y se contempla un momento en el espejo apenas advirtiendo que su amante se ha ido y su cerebro filtra trabajosa una idea:

"Bueno, asunto concluido, menos mal que ha pasado".

Cuando una mujer hermosa ha tocado la locura y recorre nuevamente la soledad del cuarto, se alisa el cabello con un gesto automático, y pone un disco en el gramófono. 
"Esta música se deslizó hasta donde yo estaba por las

$$
\text { aguas" }
$$

y por el Strand, calle Victoria arriba.

Ah, ciudad de la City, a veces oigo

junto a una taberna de la calle Lower Thames,

el deleitoso acorde de una mandolina

y la barbulla y el parloteo del interior

donde los pescaderos ociosos se juntan a mediodía, donde los muros

del Santo Mártir sostienen

un esplendor inefable de mármoles jónicos y oro.

El río transpira

petróleo y alquitrán

las gabarras se mecen

con la marea creciente

velas rojas

desplegadas

a sotavento, se mecen en la pesada verga.

Las gabarras arrastran

troncos a la deriva

Greenwich abajo

más allá de la isla de los Perros.

\section{Ueialala leia}

Uallala leialala

Elizabeth y Leicester

le daban a los remos

toda la popa era

una concha dorada

gules y oro

la cóncava marola

ondulaba en las riberas

el viento suroeste

empujaba río abajo

los broncialados ecos

de blancos campanarios

Ueialala leia

Uallala leialala

"Tranvías y polvorientos árboles.

Highbury me hizo. Richmond y Kew 
me deshicieron. Por Richmond me abrí de piernas

boca arriba en el fondo de una barca mezquina".

"Los pies tengo en Moorgate y el corazón

bajo los pies. Después de aquello

él lloró. Me prometió recomenzar.

Yo ni despegué los labios. ¿De qué me iba a quejar?"

"Allá por las dunas de Margate.

No consigo relacionar

nada con nada.

Las uñas rotas de unas manos sucias.

Mi gente, gente humilde que no espera

nada."

la la

A Cartago fui entonces

ardiendo ardiendo ardiendo ardiendo

Ay, Señor tú me arrancas

Ay, Señor tú me arrancas

ardiendo

\section{MUERTE POR AGUA}

Flebas el Fenicio, que lleva dos semanas muerto,

se olvidó del chillido de las gaviotas y de las olas del insondable mar

y de las ganancias y de las pérdidas.

acogió su osamenta rumorosa. Con los vaivenes

hizo el camino de su edad y juventud

para entrar en el vórtice.

Una corriente submarina

Tú que giras el timón oteando a barlovento,

Gentil o judío

acuérdate de Flebas que fuera alto y apuesto como tú. 


\section{LO QUE DIJO EL TRUENO}

Detrás de las antorchas que enrojecen los rostros sudorosos

detrás del helado silencio en los jardines

detrás de la agonía en los pedregales

del grito y del llanto

prisión y palacio y del retumbar

del trueno en primavera sobre remotas montañas

el que vivía está ahora muerto

nosotros que vivíamos nos morimos ahora

con un poco de paciencia

Aquí no hay agua sino sólo roca

roca y no agua y el camino polvoriento

el camino que serpea ascendiente entre montañas

pedregosas montañas sin agua

si hubiera agua nos detendríamos a beber

en la roca uno no puede pararse ni pensar

se suda sal y los pies se cuecen en la arena;

si al menos hubiera agua en esa roca

muerta montaña cuya boca de cariados dientes no puede ni escupir

aquí uno no puede pararse, echarse ni sentarse

ni siquiera hay silencio en las montañas

sino el seco y estéril trueno sin lluvia

ni siquiera hay soledad en las montañas

sino hoscos rostros enrojecidos, desdén y gruñidos

desde los umbrales de cuarteadas chozas de barro

y no roca

Si hubiera agua

si hubiera roca

y agua además

y agua

un manantial

un remanso entre las rocas

aunque sólo fuera el rumor del agua

y no el de la chicharra

y el murmullo de la agostada hierba

sino el barboteo del agua sobre la piedra

donde el tordo canta en los pinares

glu glu glu glu glu glu glu

pero no hay agua

¿Quién es ese tercero que siempre camina a tu lado? 
Cuando cuento sólo vamos tú y yo

pero cuando elevo la mirada al horizonte de este blanco sendero

siempre hay otro que camina a tu lado

sigilosamente, envuelto en una capa parda, embozado

no sé si hombre o mujer

Pero ¿quién es ese que va a tu otro lado?

¿Qué es ese rumor alto en el aire?

Murmullos de lamentos maternales.

¿Qué turbas son esas de encapuchados que hormiguean torpemente sobre la tierra agrietada cubriendo llanuras

infinitas

sólo limitadas por el horizonte de mi mirada?

¿Qué ciudad es aquella tras las montañas

grietas, remiendos y súbitas ruinas en el aire violeta

torres desmoronándose?

Jerusalem Atenas Alejandría

Viena Londres

ensueño.

Una mujer tensó su endrina cabellera

y pulsó suave música en tan sutiles cuerdas

y murciélagos con rostros infantiles en el fulgor violeta chillaban y aleteaban

y se colgaban cabeza abajo por los oscuros antros

y el aire se llenaba de torres invertidas

campanas repicando reminiscentes horas

coros de voces salen de los secos aljibes y los exhaustos

pozos.

En este putrefacto agujero entre montañas

a la débil luz de la luna, la hierba entona voces

sobre ruinosas tumbas, cerca del santuario

El santuario vacío, morada sólo de los vientos.

Sin ventanas, con la puerta batiendo,

los desecados huesos no harán a nadie mal.

Sólo un gallo se erguía en la viga cumbrera

kikirikiiiiii

al destello de un relámpago. Después una húmeda ráfaga

trajo la lluvia.

El Ganges se hundió y las hojas caidas

aguardaban la lluvia mientras las nubes negras

se remansaban a lo lejos más allá del Himavant.

La jungla se agazapaba, tensa en el silencio.

Entonces habló el trueno 
$D A$

Datta: ¿qué hemos dado?

Amigo mío, la sangre me batanea el corazón el infame atrevimiento de una fugaz entrega que toda una eternidad de prudencia no podrá borrar por eso y sólo por eso hemos existido aunque no lo recogerán nuestras necrológicas ni nuestros epitafios adornados por la benéfica araña ni bajo sellos rotos por un macilento notario en nuestros cuartos vacíos.

$D A$

Dayadhvam: He oído la llave girar en la cerradura una vez y solamente una pensamos en la llave cada cual en su cárcel y pensando en la llave cada cual se encarcela sólo al caer la noche rumores etéreos evocan un momento un roto Coriolano

$D A$

Damyata: La barca respondió alegremente a la mano experta en vela y remos la mar estaba en calma, tu corazón habría respondido alegremente, de haberlo invitado, palpitando sumiso

a las hábiles manos

Me senté en la orilla

a pescar, con la árida llanura a mi espalda

¿Pondré en orden mis tierras finalmente?

El Puente de Londres se hunde se hunde se hunde

Poi s'ascose nel foco che gli affina

Quando fiam uti chelidon -ah, golondrina golondrina

Le Prince d'Aquitanie a la tour abolie

He apuntalado mis ruinas con estos fragmentos

¡Cómo, entonces os conviene. Hieronymo se ha vuelto otra vez loco.

Datta. Dayadhvam. Damyata.

Shantih shantih shantih 
Juan Eslava Galán (born in Arjona, Jaén, ·3-7- 1948) studied Modern Philology at the University of Granada. He studied translation at Aston University (Birmingham, England), and got a PhD thesis in Medieval History (Poliorcética y fortificación bajomedieval en el reino de Jaén). Having spent his career as a teacher of English, he returned to his earlier interests as a writer of historic genre, both fiction and non-fiction. He has authored more than ninety essays and novels (some under the pen names Nicholas Wilcox, Ramón J. Uribe, Carmela Ribó y Jaume Pi i Bofarull) and has translated texts of T.S. Eliot, William Jacob, Washington Irwing, Alexander, Slidell, Richard Ford, George Borrow and Augustus.J.C. Hare. Now is a full-time writer and adds cooking to his pursuits

Nadia López-Peláez Akalay is a BA last-year student in English Studies at the Universidad de Granada and Trinity College Dublin (Ireland). She has taken part in a few international and national conferences on literature, ecology and feminism. Ms López-Peláez Akalay is currently working on her BA thesis on Irish poetry and culture, as well as collaborating with the organization of the VI International Conference on Irish Studies. She has also obtained the 2018 Poetry Award of the Faculty of Philosophy and Humanities at the Universidad de Granada. Poems by Ms López-Peláez will appear in the next issue of the prestigious Dublin literary review Icarus (2021, 70:2). 